\title{
NOTAS MICOLOGICAS VI: SELECCION DE MICROHONGOS ASOCIADOS A MATERIAL VEGETAL Y QUERATINA DESDE ARGENTINA Y CHILE
}

\author{
(Mycological notes: A selection of microfungi associated with vegetal material \\ and keratine from Argentina and Chile)
}

\author{
*Eduardo Piontelli,L. \& **Gustavo Giusiano \\ *Universidad de Valparaíso, Escuela de Medicina, \\ Cátedra de Micología, Casilla 92 V. Valparaíso, Chile. email- eduardo.piontelli@uv.cl \\ **Universidad Nacional del Nordeste, Inst. Med. Reg. Departamento de Micología \\ Av. Las Heras 727, 3500 Resistencia (Chaco), Argentina.
}

Palabras clave: Microhongos,Pullospora macrospora, Sarcopodium macalpinei, Clonostachys rosea f. rosea, C. compactiuscula, C. rogersoniana, C. rhizophaga (similis), Microsporium vanbreuseghemii (similis), Curvularia catenulata.

Key words: Microfungi, Pullospora macrospora, Sarcopodium macalpinei, Clonostachys rosea f. rosea, C. compactiuscula, C. rogersoniana, C. rhizophaga (similis), Microsporium vanbreuseghemii (similis), Curvularia catenulata.

RESUMEN

Durante el año 2003 en diversas investigaciones en curso relacionadas con la la micota epífita de Pinus canariensis de la zona de Misiones (Argentina), la queratinofílica y la endófita de la zona central de Chile, han permitido reunir un grupo interesante de hongos integrantes de 5 géneros, que merecen ciertos comentarios ya sea por ser poco comunes o raros. Entre ellos: Pullospora macrospora, Sarcopodium macalpinei, Clonostachys rosea $f$. rosea, C. compactiuscula, C. rogersoniana, C. rhizophaga (similis), Curvularia catenulata y una cepa heterotálica de Microsporum, un taxa cercano a M. vanbreuseghemii o M. racemosum, dos representantes no descritos aún en nuestro país. Esta cepa que presenta cierto grado de polimorfismo y datos fisiológicos no coincidentes para una clara determinación morfológica, se envió a centros de referencia internacionales para pruebas de cruzamientos o moleculares.

Continuando con las investigaciones en microhongos en diversos substratos, estas notas guardan relación con un grupo selecto de aislamientos que tienen cierto interés taxonómico por su escasa distribución, caracteres particulares de sus formas anamorofas o que han presentado recientes cambios o actualizaciones en sus monografías. La mayoría de los aislamientos se realizaron en la zona Norte de Argentina y en la zona central de Chile.

\section{ABSTRACT}

During 2003 in several current research work regarding the epiphyte mycota of Pinus canariensis from the zone of Misiones (Argentina), the keratinophilic and endophyte mycota from the central zone of Chile, have made it possible to identify an interesting group of fungi belonging to 5 genera that are worthy to be referred to either because they are not very common or are rare. Among them:Pullospora macrospora, Sarcopodium macalpinei, Clonostachys rosea f.rosea, C.compactiuscula, C.rogersoniana, C.rhizophaga (similis), CurvuIaria catenulata, and an heterotallic strain of Microsporum, a taxa near to M.vanbreuseghemii or M.racemosum, two representatives that have not been still described in our country. This strain bearing certain degree of polymorphism and physiological data that are not coincident for a clear morphological determination was sent to international reference centers in order to carry out cross or molecular tests.

Pullospora macrospora Nag Raj, Coelomycetous anamorphs with appendage-bearing conidia, 1993 (Figura 1-1,2).

Conidioma picnidial, negro, solitario, inmerso parcialmente en el substrato, con parte de su cuello visible, de aspecto piriforme con su vientre redondeado $120-230 \mu \mathrm{m}$, unilocular, glabro, con peridio externo formado por células café de paredes gruesas y de textura angularis y células 
cordones especialmente en agar avena, en CMA escaso micelio aéreo. Reverso blanco a crema. Con el tiempo y en presencia de luz en los 2 medios, las colonias se vuelven rosadas en su anverso y reverso. Conidióforos primarios y secundarios hialinos, de dos tipos: los verticilados son abundantes en el margen de la colonia y en menor cantidad hacia el centro. Bajo la lupa estereoscópica (40x), se aprecian sus formas ramificadas en verticilio en la parte más alta del conidióforo y sus falsas cabezas conidiales en pequeñas gotas hialinas en cada extremo de la célula conidiógena que contienen conidios unicelulares, hialinos. Conidióforos secundarios de aspecto bi o terverticilados, solitarios o en grupos, que nacen del substrato o de los cordones de hifas del micelio aéreo, con ramas y fiálides comprimidas, algunas ramas divergentes. La parte basal del conidióforo más ancha (3,5-5,5 $\mu \mathrm{m})$, se adelgaza hacia los ápices. Fiálides derechas o levemente curvas hacia la línea central, de cuello largo y más anchas cerca de la base, sin collarete visible, 6-12 x 1,5-2,5 $\mu \mathrm{m}$. Conidios desde los conidióforos secundarios reunidos en masas mucosas de color rosa pálido, dispuestos en columnas imbricadas unicelulares, hialinos, mas o menos elípticos, con la cara ventral derecha o levemente curva y la dorsal curva y con un hilum lateralmente desplazado y una media entre largo y ancho de 5,8 x 3,1 $\mu \mathrm{m}$ (Tabla 1).

A pesar que el origen de los aislados fue diversificado, las diferencias morfológicas de las colonias y sus estructuras reproductivas fueron bastante similares. Todas las cepas analizadas en subcultivos $(n=9)$ se tornaron rosadas en el tiempo, en especial cuando las placas permanecieron a la luz del día, sin embargo, el pigmento no difundió al medio. En dos de las cepas chilenas, los conidios provenientes de conidióforos secundarios, fueron levemente más grandes, pero la cepa 6, proveniente de acículas desde Argentina es bastante similar (Tabla 1). Estas variaciones que parecen de mayor tamaño que los estándares en la literatura, parecen asociarse a ecotipos diversos, hospederos distintos, o a las mediciones de pocos conidios. La distribución de $\boldsymbol{C}$. rosea $\mathrm{f}$. rosea es muy abundante en Chile, ya sea desde el suelo, substratos vegetales en descomposición y corteza de árboles (comunicación personal primer autor), incluso la cepa enviada por G. Grinsberg al CBS (CBS 222,93) fue aislada en Pinus radiata. Al parecer C. rosea f. rosea es la especie dominante. En la literatura chilena, aparentemente no existen descripciones de otras especies del género.

Clonostachys compactiuscula (Sacc.) D.Hawkswoprth \& W.Gams in Hawksworth \& Punithalingam Trans. Br. mycol.Soc. 64:90. 1975 (Figura 2.- 12,13) = Verticillium compactiusculum Sacc. = Gliocladium cylindrosporum (G.Arnaud)Matsush.

Para otros sinónimos ver Schroers, 2001.
Colonias en agar avena de 30 a 40 mm en 8 días a $25^{\circ} \mathrm{C}$, blancas a crema, de aspecto plano, con poco micelio aéreo, levemente cordonoso, con tendencia a formar círculos concéntricos de crecimiento, reverso pálido a crema amarillento. En presencia de luz se torna la colonia y el reverso de color salmón pálido. Conidióforos dimórficos, con dominancia de los secundarios y escasos o ausentes los primarios, dispuestos en la superficie del agar y en el micelio aéreo o en las hifas en fascículos, ramificados, con estipe relativamente largos 70 - $90 \mu \mathrm{m}$, con fiálides en grupos comprimidos, divergentes, delgadas, hacia el ápice 7-14 x 2-2,5 $\mu \mathrm{m}$ en la base, que producen masas conidiales de color crema a anaranjadas en el tiempo, dispuestas en imbricadas columnas, fiálides intecalares frecuentes. Conidios hialinos, lisos, elipsoidales, a cilíndricos, derechos, con sus extremos redondeados, con un hilum desplazado lateralmente, reunidos en masa, generalmente entre 8-12 x $2-2,5 \mu \mathrm{m}$. Ausencia de peritecios y esporodoquios. Estroma a veces presente en los cultivos viejos compuesto de células de aspecto pseudoparenquimatoso.

C. compactiuscula, se aisla del suelo, pero es un hongo poco común y se diferencia por sus conidios cilíndricos y ausencia de conidióforos primarios semejantes a verticillium. Tubaki (1963), clasificó las especies japonesas bajo el nombre de $\boldsymbol{C}$. cylindrospora Arnalud, pero estas se tranfirieron a $\boldsymbol{C}$. compactiuscula, sin embargo, parece haber un consenso en reconsiderar estas cepas. Schimmel et al.(1997), obtuvieron de $\boldsymbol{C}$. compactiuscula una esterasa que selectivamente hidroliza el levostatin, un agente clínico usado como agente antihipercolesterolémico. Las cepas de esta especie fueron la que mostraron gran variabilidad en la producción de mitosporas (Tabla 1).

\section{Clonostachys rhizophaga (similis)(Tehon} \& Jacobs) Schroers ?. Stud. Mycol.45:85 (2001) (Figura 2.10,11). = Verticillium rhizophagum Tehon \& Jacobs.

Colonias en agar avena de 40-50 mm en 8 días a $25^{\circ} \mathrm{C}$, blancas a crema, de aspecto lanoso a fuertemente cordonoso, con tendencia a formar círculos concéntricos de crecimiento, reverso pálido a crema amarillento. En presencia de luz se torna la colonia y el reverso de color salmón pálido. Conidióforos dimórficos, con dominancia de los primarios semejantes a verticillium, dispuestos en la superficie del agar y en el micelio aéreo o en las hifas en fascículos, con fiálides delgadas, divergentes, rectas, que producen conidios reunidos en pequeñas gotas transparentes. Conidióforos secundarios escasos, penicilados, con ramas divergentes, fiálides en racimos laxos (5-7), más anchas en su base y adelgazándose hacia el ápice, sin exhibir un collarete conspicuo, 11-19 $\mu \mathrm{m}$ de largo x 2-3 $\mu \mathrm{m}$ de ancho en la base. Fiálides intercalares escasas. Conidios en conidióforos secundarios, hialinos, lisos, elipsoidales, 
internas, pálidas y de paredes más delgadas. Conidióforos hialinos, adheridos a las paredes internas, poco ramificados, septados de paredes finas, 30-50 $\mu \mathrm{m}$ de largo. Células conidiógenas integradas o terminales, cilíndricas, incoloras de paredes delgadas 10 a 22 x 2-3,5 $\mu$ m, con tendencia a proliferar. Conidios cilíndricos, de ápices redondeados, unicelulares, hialinos, lisos, 22-27 x 5-6 $\mu \mathrm{m}$, que dan origen a apéndices primarios en posición central y apéndices secundarios subpolares no ramificados, filamentosos y de puntas delgadas y base más ancha 3-4 en número. Aislado de Pinus canariensis (Argentina).

El género Pullospora fue creado por Laurel \& Schotter (1965), como un género monotípico que incluía la especie coprófila $\boldsymbol{P}$. tetrachaeta, hasta que Nag Raj (1993), incluye otra especie también de hábitat coprófilo (roedores). A pesar que nuestro aislamiento se efectuó sobre substrato vegetal (acículas de pino), puede asociarse a la presencia de varios tipos de roedores que habitan en el área muestreada. El holotipo de esta especie fue aislado en San Bernardino (California) y no hemos encontrado nuevas referencias en la literatura sobre la distribución de esta especie, por lo tanto el hemisferio sur (Argentina) sería otro punto geográfico que puede sugerir una dispersión en climas cálidos o tropicales.

Sarcopodium macalpinei (Agnohothrudu \& Barua) Sutton. Trans. Br. mycol. Soc. 76:97-102 (1981) (Figura 1.-3,4,5,6)

=Kutilakesopsis macalpinei Agnohothrudu \& Barua. J.Ind. Bot.Soc. 36:309 (1956) as “macalpineae”.

Colonias en PDA de crecimiento moderado 30 $35 \mathrm{~mm}$ en 10 días a $25^{\circ} \mathrm{C}$ con producción de micelio hialino septado, liso, de aspecto lanoso, solevantado en el centro, de color canela amarillento claro. Reverso pálido a cafesoso. Con el tiempo el centro de la colonia presentó un aspecto más granuloso y mucoide debido a la presencia de abundantes esporodoquios, cupulados, setosos gregarios a confluentes que nacen adosados principalmente al micelio aéreo. Las setas nacen del micelio cercano al conidióforo, de los penicillios o cerca de la base del conidióforo, derechas cerca de su lugar de nacimiento, pero onduladas a circinadas hacia el ápice obtuso, no ramificadas, septadas, de color verde pálido a café, oscureciéndose hacia el ápice, verruculosas, que sobresalen de la masa mucoide, con 4 a 6 septos, 5-6 x $90-185 \mu \mathrm{m}$. Conidióforos bién diferenciados, irregularmente ramificados en forma penicilada, derechos a flexuosos, hialinos, lisos, con células conidiógenas monofialídicas agrupadas en racimos laxos, terminales o laterales, cilíndricas, aguzándose en el ápice, hialinas, lisas, que cubren la parte superior del conidioma, 13-24 $\mu \mathrm{m}$ de largo y 2,8-3 $\mu \mathrm{m}$ de ancho en la base, con un engrosamiento periclinal en el ápice. Conidios en masas mucoides de color canela amarillento, principal- mente elípticos y derechos, pero algunos con leve tendencia a curvarse, hialinos, lisos, con un septo mediano, sin gútulas y obtusos en ambos extremos, pero a veces con su base más aplanada por la cicatriz de separación esquizolítica, 9-14 x 3-3,5 $\mu \mathrm{m}$.

Alfieri \& Samuels (1979), describen una nueva especie de Nectriella (N. pironii) en arbustos ornamentales y otros vegetales, una especie que se distingue de las otras del género por ser la única que produce en forma constante agallas en sus plantas hospedero y un anamorfo con conidiomata semejante a Kutilakesa. Aunque este anamorfo no se presenta en las otras especies de Nectriella, sus esporodoquios son bastante más conspicuos que los ascomata, pero ambos se forman simultáneamente. Estos autores acomodaron el nombre del anamorfo en Kutilakesa Subramanian, porque sus conidiomas son claros en color, mientras los de Sarcopodium Ehremb. ex Schlech. son generalmente oscuros con conidios unicelulares y los de Kutilakesiopsis Agnihothrudu \& Barua son bicelulares. Posteriormente denominada como Kutilakesa pironii Alfieri (Mycotaxon 10:217, 1979).

Dos años más tarde Sutton (1981), pone en sinonimía con Sarcopodium los nombres genéricos de Tricoleconium, Periolopsis, Actinostilbe, Kutilakesa y Kutilakesopsis. Al mismo tiempo redescribe 2 especies en Sarcopodium con conidios con 1 septo: $\boldsymbol{S}$. vanillae (Petch) Sutton (= Actinostilbe vanillae Petch) y S.macalpinei (Agnihothrudu \& Barua) Sutton (=Kutilakesopsis macalpineae Agnihothrudu \& Barua).

Watanabe (1993), describe una nueva especie de Sarcopodium (S.araliae) en Aralia elata desde japón e incluye en su trabajo una clave útil de todas las especies descritas a la fecha.

Sarcopodium macalpinei, parece tener una distribución limitada a zonas cálidas o tropicales, principalmente la India y Brasil (Sutton, 1981); como nuestro aislado que proviene también de una zona pantrópica como es Misiones (Argentina). Su hábitat parece asociado a restos vegetales en el suelo o como epífito de las superficies de tallos y hojas de diversas plantas. Guarro et al.(2002), describen una nueva especie de Sarcopodium (S.oculorum Gené \& Guarro), desde un ulcera corneal en un niño brasilero, demostrando el oportunismo de algunos integrantes de este género.

Clonostachys rosea f. rosea (Link:Fr.) Schroers, Samuels, Seifert \& W. Gams (1999). Sinónimos obligados =Penicillium roseum Link,=Gliocladium roseum (Link) Thom . (Figura 2.- 7,8,9)

Listado de sinónimos facultativos en Schroers, 2001.

Colonias de crecimiento rápido en Agar avena y CMA (Tabla 1) en 8 días a $25^{\circ} \mathrm{C}$, de color blanco-cremoso con micelio hialino, de aspecto tomentoso y agrupado en 
terminan en métulas menos divergentes. Estipes relativamente largos 90-130 $\mu \mathrm{m}$, con fiálides en grupos comprimidos, divergentes, delgadas, hacia el ápice 12-14x 2-2,7 $\mu$ m, que producen masa conidiales de color blanco-cremoso a anaranjadas en el tiempo, dispuestas en imbricadas columnas, fiálides intecalares frecuentes. Conidios hialinos, lisos, ampliamente elipsoidales, a ovales, derechos, con sus extremos redondeados, con un hilum desplazado lateralmente, reunidos en masa, generalmente entre 4,7 8,4 x 2,1- $3 \mu \mathrm{m}$. Ausencia de peritecios y esporodoquios.

C.rogersoniana es similar a C.compactiuscula en los patrones de ramificación de los conidióforos y en la frecuencia de sus conidióforos primarios (abundantes en la primera especie), pero tambien en las dimensiones de sus conidios que son más cortos y oblongos. Es una especie de más amplia distribución especialmente en el suelo, raíces, corteza muerta o desde la litera vegetal, especialmente en climas cálidos o tropicales.

Un completo panorama histórico, ecológico y los conceptos genéricos de la separación entre Gliocladium y Clonostachys se describen ampliamente en Schroers et al. (1999) y para la separación de las especies aisladas nos basamos principalmente en la monografía de Schroers (2001). Este último autor, revisa y clasifica las especies de Bionectria (Hypocreales, Bionectriaceae) con anamorfos en Clonostachys, ordenando los teleomorfos de Bionectria en 6 subgéneros basándose en la morfología del estroma, la anatomía del peritecio y las ascosporas en su substrato natural, complementándola con su biología molecular, delimita ampliamante a Clonostachys de géneros semejantes clasificados en Verticillium, Gliocladium, Acrostalagmus, Sesquicillium, Myrothecium, Verticilliodochium, Clonostachyopsis, Dendrodochium y Spicaria (los últimos 4 considerados sinónimos de Clonostachys por Schroers et al.,1999; Schroers,2001). Nuestros aislamientos pertenecen exclusivamente al subgénero Bionectria.

El género Gliocladium Corda, s.str., ha sido circunscrito para los anamorfos de Sphaerostilbella e Hypocrea serie Pallidae Doi (Hypocreaceae), que generalmente se presentan sobre los basidiomas de los Aphyllophorales (Seifert, 1985; Schroers et al.,1999; Schroers, 2001). Existe un buen número de taxa fúngicos semejantes a gliocladium y sus características polifiléticas han sido demostradas por biología molecular ( Rehner \& Samuels, 1994).

Las especies de Bionectria/Clonostachys, son consideradas dentro de diversas categorías econutricionales, desde saprotrofos, micoparásitos destructivos, liquenícolas o habitantes de árboles y de hojas en proceso de descomposición. Como micoparásitos, C.rosea y C.catenulata (anteriormente Gliocladium roseum y G.catenulatum), son conocidos agentes de control biológico frente a varios Ascomycetes y sus anamorfos, Basidiomycetes,
Omycetes, Myxomycetes, así como de huevos de nemátodos ( Domsch et al., 1980; Rogerson \& Stephenson, 1993; Schroers, 2001). Sin embargo, frente a sus reconocidas capacidades saprotróficas o micoparasíticas, las habilidades fitoparasíticas de las especies de Bionectria/ Clonostachys parecen ser ocasionales o actuar como patógenos secundarios. La abundante presencia de varias especies, en especial $\boldsymbol{C}$.rosea y $\boldsymbol{C}$. compactiuscula en las acículas de Pinus canariensis en Argentina, llama la atención por ser un hábitat poco descrito en la literatura. Su presencia en coníferas puede deberse a una colonización desde el suelo forestal, derivada de algunos Basidiomycetes micorricicos que fructifican en las cercanías de estos árboles.

Todas las especies de Bionectria/Clonostachys registradas en Tabla 1, permitieron observar su gran variabilidad en la producción de mitosporas, en especial en C.rosea f. rosea y $C$. compactiuscula como se comenta en la literatura (Schroers,2001).

Microsporum vanbreuseghemii (similis) Georg, Ajello, Friedman \& Brinkman, Sabouraudia,1962, 1:189-196 (Figura 3.- 16,17)

Teleomorfo Arthroderma grubyi (Georg, Ajello, Friedman et Brinkman) Ajello, Weitzman, McGinnis et Padhye. Mycotaxon 25:505-518(1986).

Colonia en PDA a $25^{\circ} \mathrm{C}$, de crecimiento relativamente rápido (33 a $35 \mathrm{~mm}$ en 10 días), plana a pulverulenta por la abundante producción de macro y microconidios, levemente algodonosa en la periferia, blanquecina a cremosa, con reverso crema a amarillento, pero en el tiempo tiende a dar una mezcla de pigmentos rojo-vináceos. Microscópicamente presenta hifas hialinas delgadas septadas con conidióforos indiferenciados en cortos o largos pedicelos que originan macroconidios apicales o laterales en las hifas fértiles, dispuestos en racimos, pequeños grupos o solitarios, de aspecto fusiforme a cilíndricos cuando jóvenes, de ápices redondeados, de paredes gruesas $(3-4 \mu \mathrm{m})$ finamente rugosas, con 5 a 11 septos de menor grosor que las paredes, $40-73$ (58) x $10-$ 14(13) $\mu \mathrm{m}$, sin apéndices filiformes en sus ápices (incluso en los otros medios usados: Agar Sabouraud, agar Malta y agar Bromocresol púrpura caseina glucosa). Se observa la presencia de hifas en raqueta. Microconidios abundantes, no agrupados en racimo, que nacen en su mayoría directamente en ángulo recto sobre las paredes de las hifas, o sobre cortos pedicelos, unicelulares, clavados a piriformes, escasamente de forma ovoide, de base trunca, variables en tamaño, generalmente entre 3,5-6 (-10) x 2$3 \mu \mathrm{m}$.

Teleomorfo ausente (heterotálico) en cultivos y sobre el substrato queratínico; no se observaron órganos de perforación en el pelo humano en el test de perforación 
Tabla 1.- Especies de Clonostachys en Agar avena y CMA (8 días a 25ㄷ): diámetro de las colonias, conidios y lugar natural de aislamiento. Mediciones basadas en un total de

30 conidios al azar /cepa

\begin{tabular}{|c|c|c|c|}
\hline \multicolumn{3}{|c|}{$\begin{array}{c}\text { Agar Av. } \quad \text { CMA } \\
\operatorname{Diam}(\mathrm{mm})\end{array}$} & Conidios en $\mu \mathrm{m} \quad$ Subst. natural \\
\hline 1. C.rosea f.rosea & 50 & 65 & 3,7 (6,25) 9,2 x 2,7 (3,10) 4,0 corteza dicotil. (Chile) \\
\hline 2. C.rosea f.rosea & 50 & 70 & $3,9(6,64) 9,6 \times 3,3(3,75) 4,2$ suelo $\quad$ (Chile) \\
\hline 3 C.rosea f.rosea & 45 & 50 & 4,5 (5,30 )6,2 x 2,5 (2.80) 3,4 Frambuesa (Chile) \\
\hline 4. C.rosea f.rosea & 45 & 50 & 3,7 (5,80) 7,0 x 2,8 (3,00).3,7 corteza, dicotil. (Chile) \\
\hline 5. C rosea f.rosea & 47 & 51 & $4,5(5,30) 6,2 \times 2,5(2,8) 3,0$ \\
\hline 6. C.rosea f.rosea & 55 & 55 & 5,3 (6,20) 7,8 x 3,1 (3,44) 4,5 acículas pino (Argen.) \\
\hline 7. C.rosea f.rosea & 56 & 55 & 2,8 (5,90) 8,1 x 2,7(3,40) 4.4 acículas pino (Argen.) \\
\hline 8. C.rosea f.rosea & 60 & 58 & $4.5(5,32) 6.5 \times 2.3(2,85) 3,5$ \\
\hline 9. C.rosea f.rosea & 55 & 45 & 4,5 (5,55) 6,2 x 2,5 (3,11) 4,0 acículas pino (Argen.) \\
\hline Datos Referencias* & & $45-57$ & $4,2(4,8-5,6) 6,6 \times 2(2,4-3) 3,4$ \\
\hline 10. C compactiuscula & 30 & 25 & 10,5 (12,20)17,0 x 2,0(2,31)3,1 acículas pino (Argen.) \\
\hline 11 C.compactiuscula & 41 & 30 & 8,1 (10,60)11,5 x 1,9(2,10)2,5 acículas pino (Argen.) \\
\hline 12 C.compactiuscula & 31 & 28 & $8,5(11,05) 14,0$ x 1,9(2,15)2,8 acículas pino (Argen.) \\
\hline 13. C. compactiuscula & 35 & 35 & $9,0(10,66) 13,0 \times 2,0(2,30) 2,8$ acículas pino (Argen.) \\
\hline 14. C.compactiuscula & 35 & 55 & $7,9(11,50) 14,8 \times 2,4(3,00) 4,2$ acículas pino (Argen.) \\
\hline 15. C.compactiuscula & 35 & 30 & $8.0(9,60) 12,0$ x 2,3(2,5)2,8 acículas pino (Argen.) \\
\hline 16. C.compactiuscula & 33 & 35 & 7,9(9,60)11,7 x 2,1(2,65)2,9 acículas pino (Chile) \\
\hline Datos Referencias* & & 25-35 & $4,0(5,4-7,5) 12,4 \times 1,9(2,2) 3,2$ \\
\hline 17. C rogersoniana & 40 & 40 & $4,7(6,35) 8,4 \times 2,1(2,6) 3,3$ \\
\hline Datos Referencias* & & $30-40$ & $4,8(5,8-7,2) 9,6 \times 2,2(3-3,8) 4,2$ \\
\hline 18. C.rhizophaga (similis) & 50 & 42 & $5(6,25) 8,0$ x 2,6 (2,90) 3,3 acículas pino (Argen.) \\
\hline 19. C.rhizophaga (similis) & 55 & 40 & $5(6.70) 8,5 \times 2,8(3,00) 3,5$ acículas pino (Argen.) \\
\hline Datos Referencias* & & $40-50$ & $4,8(5,8-7,0) 9.0 \times 2,4(2,6-3,2) 4,2$ \\
\hline * Schroers (2001) & \multicolumn{3}{|c|}{ ** Pinus canariensis C. Smith } \\
\hline
\end{tabular}

a veces curvos en su parte basal, con un hilum desplazado lateralmente, reunidos en masa, 6-7 x 2,5-3 $\mu$ m. Ausencia de peritecios y esporodoquios.

Esta especie es al parecer de distribución restringida, tiene un hábitat geofílico o asociado a restos vegetales. Se ha encontrado en Sur América tanto en Chile como en Ecuador (Schroers, 2001). Morfológicamente es muy similar a C.rosea y C.solani en el color de sus masas conidiales. Pero al parecer sus conidios se aprecian de mayores tamaños que en C.rosea. Las 2 cepas aisladas difieren levemente en las dimensiones de sus conidios. $\boldsymbol{C}$. byssicola, Schroers, C.capitata Schroers y C. rhizophaga (Tehon \& Jacobs) Schroers, presentan estructuras conidiógenas difíciles de separar morfológicamente sólo en base a sus anamorfos. Como nuestra identificación no ha incluido el análisis de secuencias de DNA que se sugiere (Schroers, 2001), como una técnica más segura para obviar ciertos caracteres crípticos de esta especie, la consideramos provisoriamente dentro de este taxon.

Clonostachys rogersoniana Schroers. Stud. Mycol.45:109 (2001) (Figura 3.-14,15).

Colonias en agar avena de 37 a 40 mm en 8 días a $25^{\circ} \mathrm{C}$, blancas a crema, de aspecto lanoso, con abundante micelio dispuesto en cordones, con tendencia a formar círculos concéntricos de crecimiento. Presencia de masas de tejido pseudoparenquimatoso en las colonias viejas, ya sea en la superficie como en la profundidad del agar, reverso pálido a crema amarillento. En presencia de luz la colonia y el reverso adquieren tonalidades de color salmón pálido. Conidióforos dimórficos en las hifas o en la superficie del agar, con dominancia de los primarios verticilados, en especial en la periferia del agar, conidióforos secundarios penicilados en menor cantidad, con ramas divergentes que 
a los 3 semanas de incubación, pero si alteración escamosa de su superficie. Si se compara con otros hongos queratinolíticos, esta especie no pertenece a los degradadores activos de la queratina como comenta Boehme \& Ziegler (1967). No produce trasparencia en los bordes de la colonia en agar Bromocresol púrpura caseina glucosa, pero produce pigmento rojo en el reverso.

La zona de su aislamiento corresponde a colinas precordilleranas en los alrededores del pueblo La Pinta (Cercano a la ciudad de Rancagua, VI Región) y no existen en la literatura nacional registros anteriores desde suelos chilenos de la zona central y norte (Piontelli et al., 1986, 1990). Es una especie poco conocida y bastante rara dentro de los hongos queratínicos geofílicos.

M. vanbreuseghemi es considerado como un hongo geofílico principalmente saprotrofo aparentemente de distribución cosmopolita, sin embargo, su asilamiento es poco común en los suelos (Domsch et al.,1980; Caretta \& Piontelli, 1975; Mercantini et al., 1986; Ogbonna \& Pugh, 1987).

Raramente causa dermatofitosis en el hombre y ocasionalmente en los animales tales como perros gatos $\mathrm{y}$ ardillas, donde aparentemente puede ser también integrante de su microbiota comensal, sin causar lesiones aparentes ( Morganti et al., 1975; Moriello \& DeBoer, 1991). Revisando los últimos 10 años de la literatura solamente pudimos encontrar 3 trabajos que citan esta especie, 2 relacionados con tinea capitis, uno en Brasil (Olivera et al.,2002), otro en Egipto (Moubasher et al.,1993) y desde suelos de la India (Rai \& Qureshi,1994).

La literatura no es acorde en muchos datos morfológicos y morfométricos de los Microsporum con grandes macroconidios en especial de $\boldsymbol{M}$.vanbreuseghemii, M.racemosus y M.praecox, estos dos últimos presentan macroconidios, más pequeños que M.vanbreuseghemii, pero con paredes más delgadas, menor cantidad de septos, formas más lanceoladas y los microconidios de ambos tienen forma de garrote (escasos en M.praecox), presentándose en racimos en M.racemosus, sobre cortos y largos pedicelos. Rebel \& Taplin (1970), diferencian M.vanbreuseghemii de M.racemosus, porque el primero tiene macroconidios con paredes más gruesas que los septos, lo que se aprecia en las microfotografías (Figura 3, 16-17). De Hoog et al.(2000), en su descripción de M.racemosus muestran macroconidios de paredes bastante gruesas y septos delgados, con medidas similares en tamaños a nuestro aislado. M.vanbreuseghemii es muy similar a Keratinomyces ajelloi, por el grosor de sus paredes, excepto que este último tiene paredes lisas y produce intensos pigmentos rojos en el reverso de las colonias, mientras el primero no siempre los produce.

Kano et al.(1997-1998), demostraron que los anamorfos y teleomorfos de Microsporum (incluyendo
Arthroderma grubyi) pueden ser identificados por amplificación al azar del DNA polimórfico (RAPD y análisis de hibridación (Southern). Gräser et al. (1999), evaluando las relaciones filogenéticas dentro de la familia Arthrodermataceae mediante estudios de ITS, confirman que A. grubyi incluye dos anamorfos (M.gallinae y M.vanbreuseghemii) confirmando lo anteriormente sugerido por Georg et al. (1962).

Los aspectos morfológicos y algunos fisiológicos, no han sido suficientes para determinar correctamente el taxon a nivel de especie. Sus características parecen acercarlo más a M.vambreuseghemii, pero en ciertos aspectos se asemeja a M.racemosus, o quizás una cepa intermedia entre ambas. En la amplificación mediante PCR para ITS1, se obtuvo un fragmento de más de 650pb con productos de digestión de 327 y 228pb, estos productos no coinciden con los esperados para Arthroderma grubii, de allí la necesidad de efectuar cruzamientos o un análisis más fino de su genotipo. Para tal efecto se envió la cepa a un centro de referencia internacional (CABI).

Curvularia catenulata Reddy \& Bilgrami 1968 Curr. Sci. 37:418. (Figura 4, 18-21)

Colonias en PDA y Malta de crecimiento rápido 4-6 cm en 5 días de aspecto algodonoso laxo, con micelio poco solevantado del agar, septado y de paredes lisas, de color oliváceo claro a café, más oscuras en Agar malta, reverso café negruzco. Conidióforos pálidos con tonos claros de café, entre 50 a $160 \mu \mathrm{m}$ de largo, poco ramificados, 4$6 \mu \mathrm{m}$ de ancho, poco geniculados y con cicatrices conidiales conspicuas. Conidios lisos, en cadenas cortas 2-4, que forman frecuentemente conidióforos nuevos desde las células apicales, que dan origen a nuevos conidios en cadenas laterales ramificadas, derechos, curvos, fusiformes o clavados, de 3 a 5 septos transversales, generalmente 3 y 4 , con células centrales más anchas y más oscuras y cierta tendencia a curvar una de sus paredes laterales, células adyacentes más pálidas, (22) 34 (55) de largo y (8)11(15) $\mu \mathrm{m}$ en la parte más ancha. Escasa presencia de stauroconidios (Figura 4.19). Clamidosporas café en cadena a veces presentes en los cultivos viejos. Aislada de una dicotiledónea (Región Metropolitana, Chile).

C.catenulata no es una especie conocida en la literatura y parece que su aislamiento sólo se ha registrado en hojas de Lagerstroemia indica en la India. Es una especie muy similar a $\boldsymbol{C}$. tritici Kumar \& Nema, aparentemente más pequeña en tamaño y menos curva, también aislada en la India desde granos de Triticum. Las diferencias de nuestra cepa con C.tritici se deben principalmente a que poseen en sus conidios en proporciones iguales 3-4 septos (algunos conidios hasta 5), mientras C.tritici posee 2 a 3 en la decripción original. Sivanesan (1987), no la incluye en sus claves y descripciones y considera a C.tritici como 


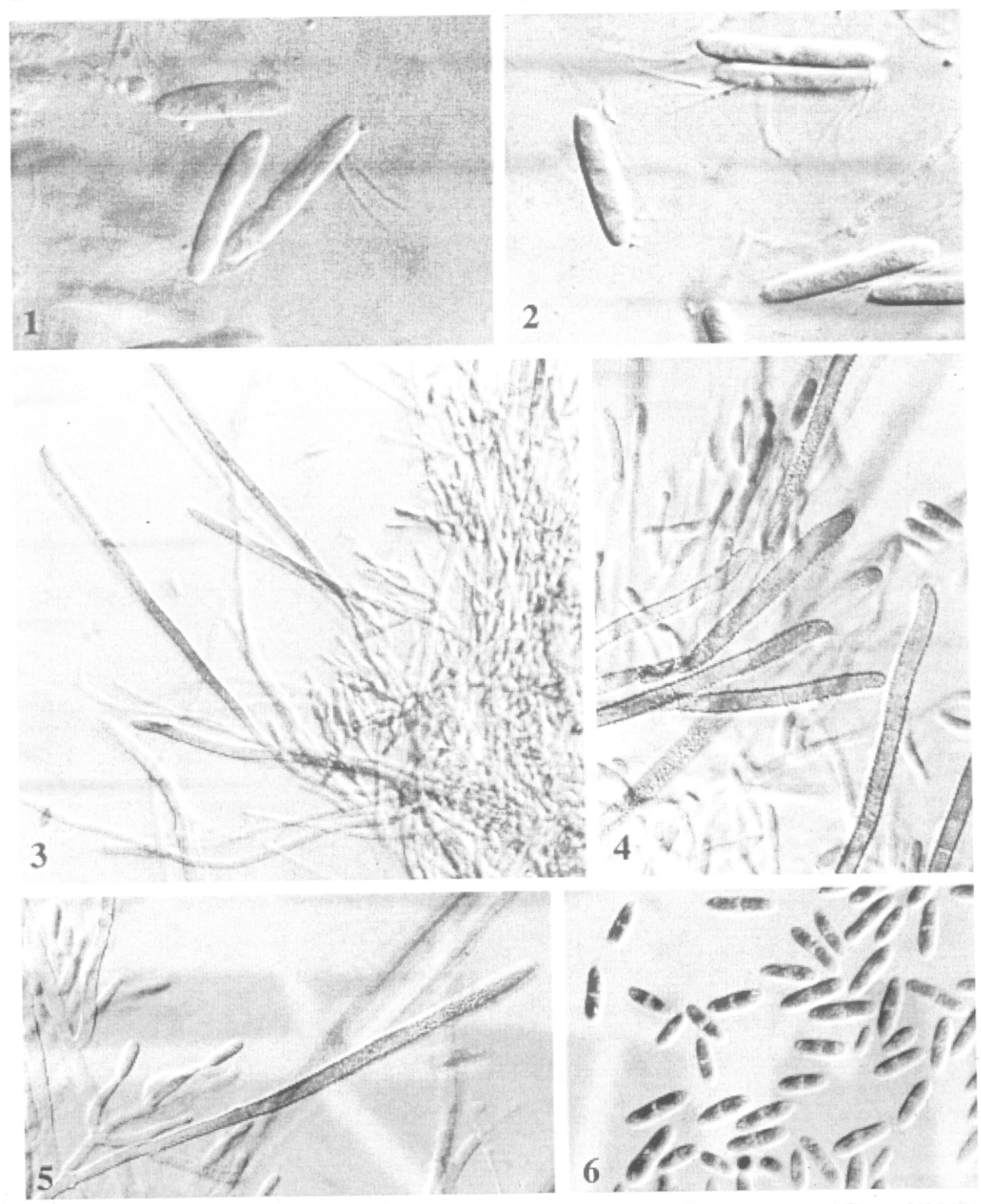

Figura 1.-(Optica DIC). 1-2. Pullospora macrospora, conidios cilíndricos que originan apéndices flexuosos, céntricos y subpolares, 1000x. 3-4-5-6. Sarcopodium macalpinei. 3. Esporodoquio mostrando setas flexuosas oscuras, fiálides y conidios, 400x. 4-5. Setas flexuosas, septadas, verrucosas y células conidiógenas, 1000x. 6. Conidios cilindricos uniseptados, 1000x. 

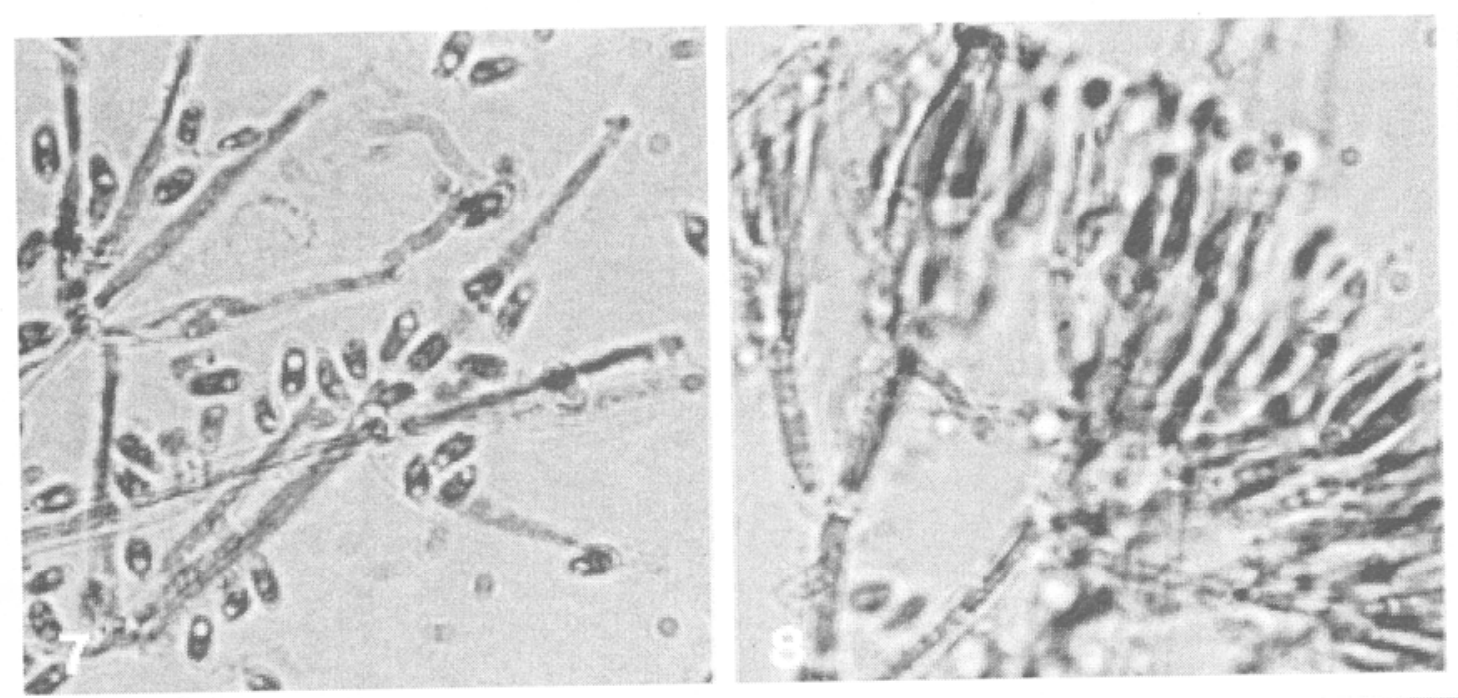

$a^{a+8}$

$\operatorname{son}_{0}$

Co. 16

cos

$90_{6}$

(2)

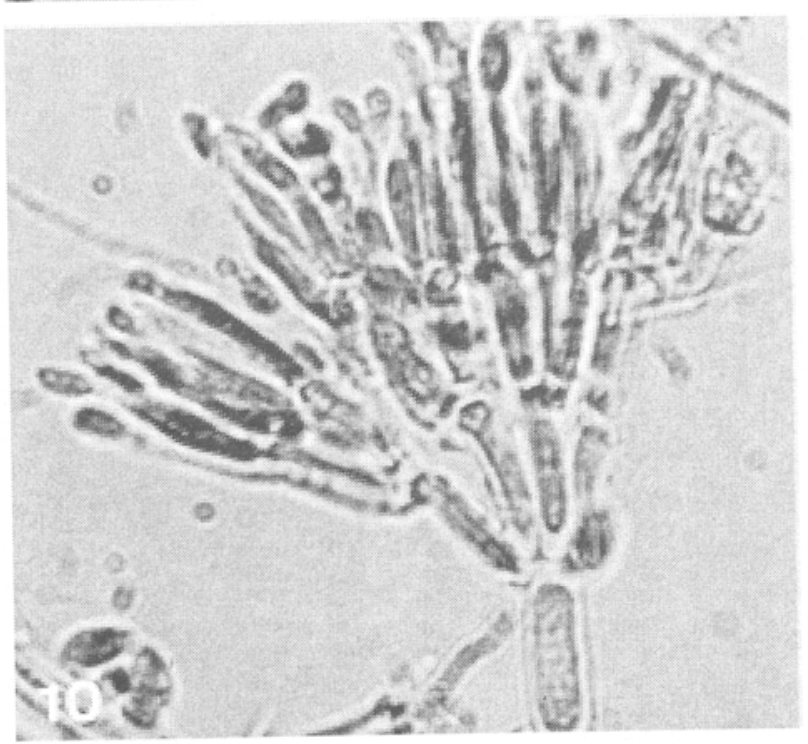

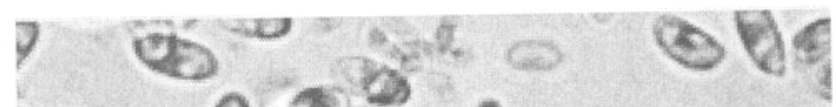

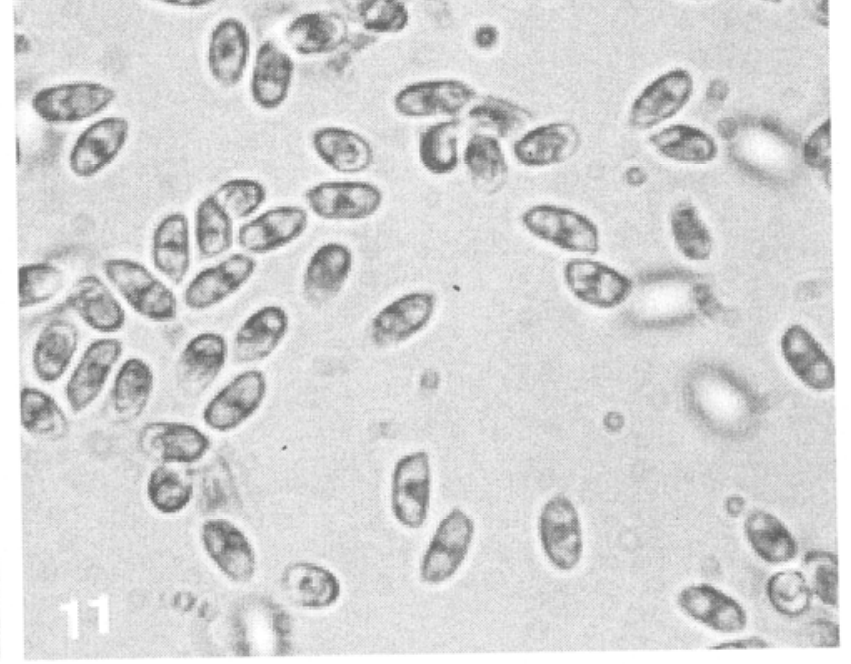

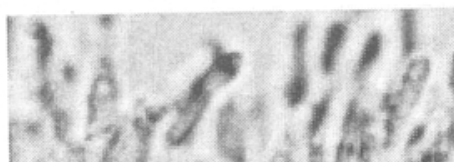

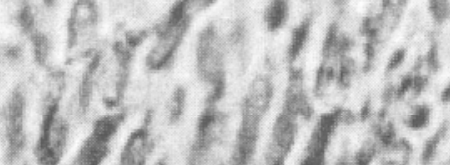

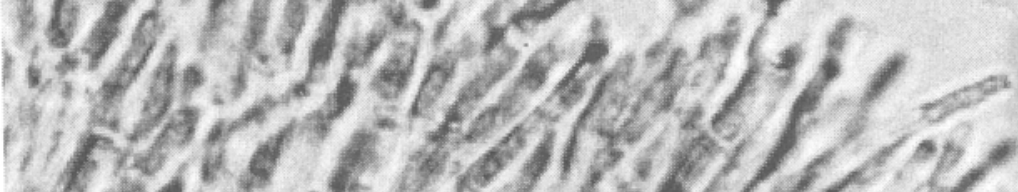

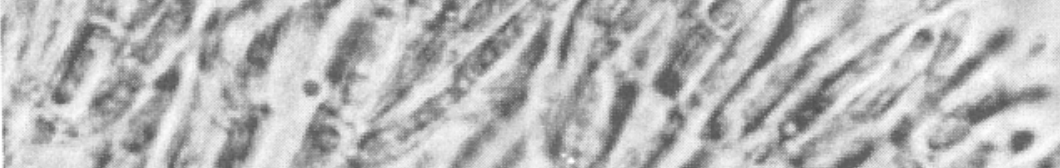
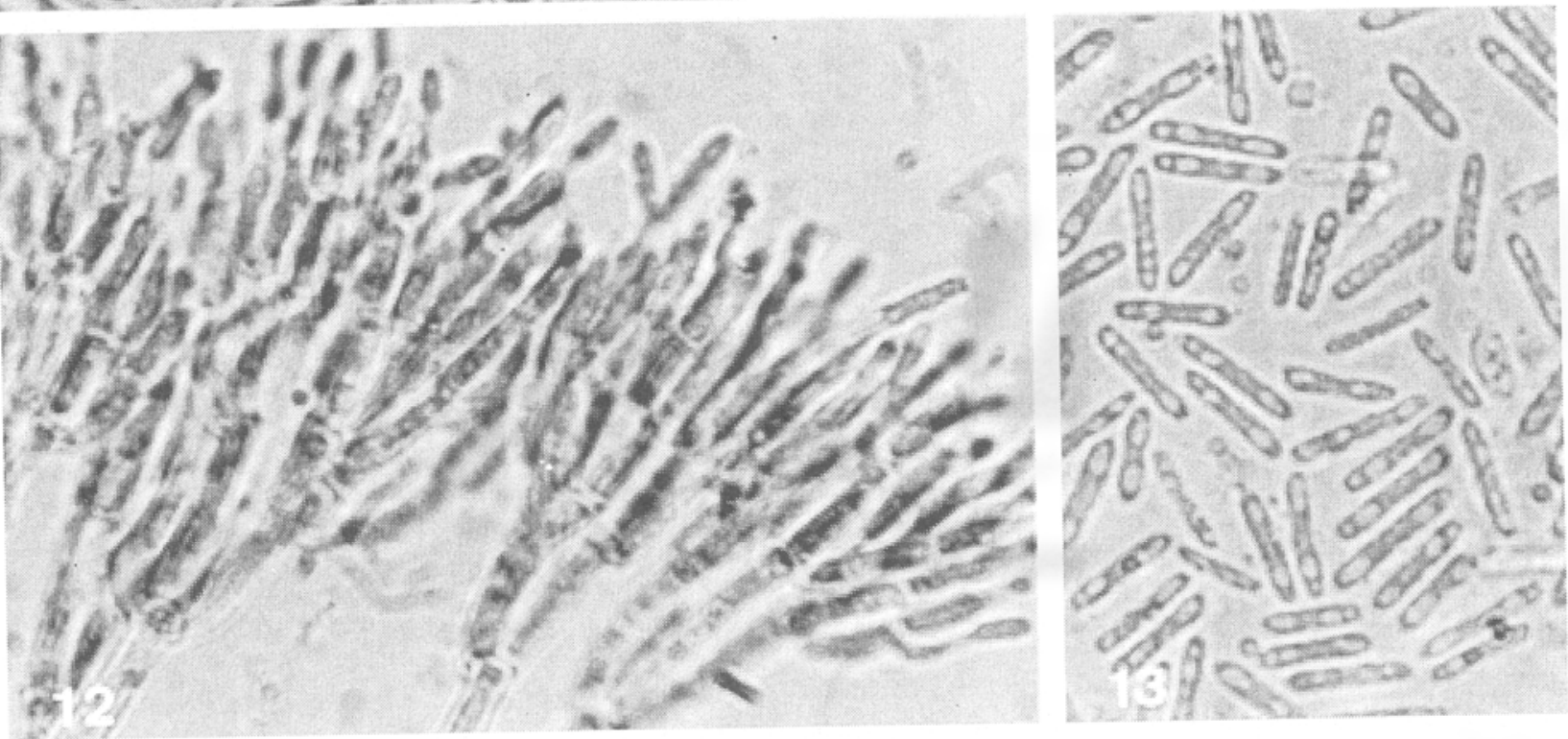

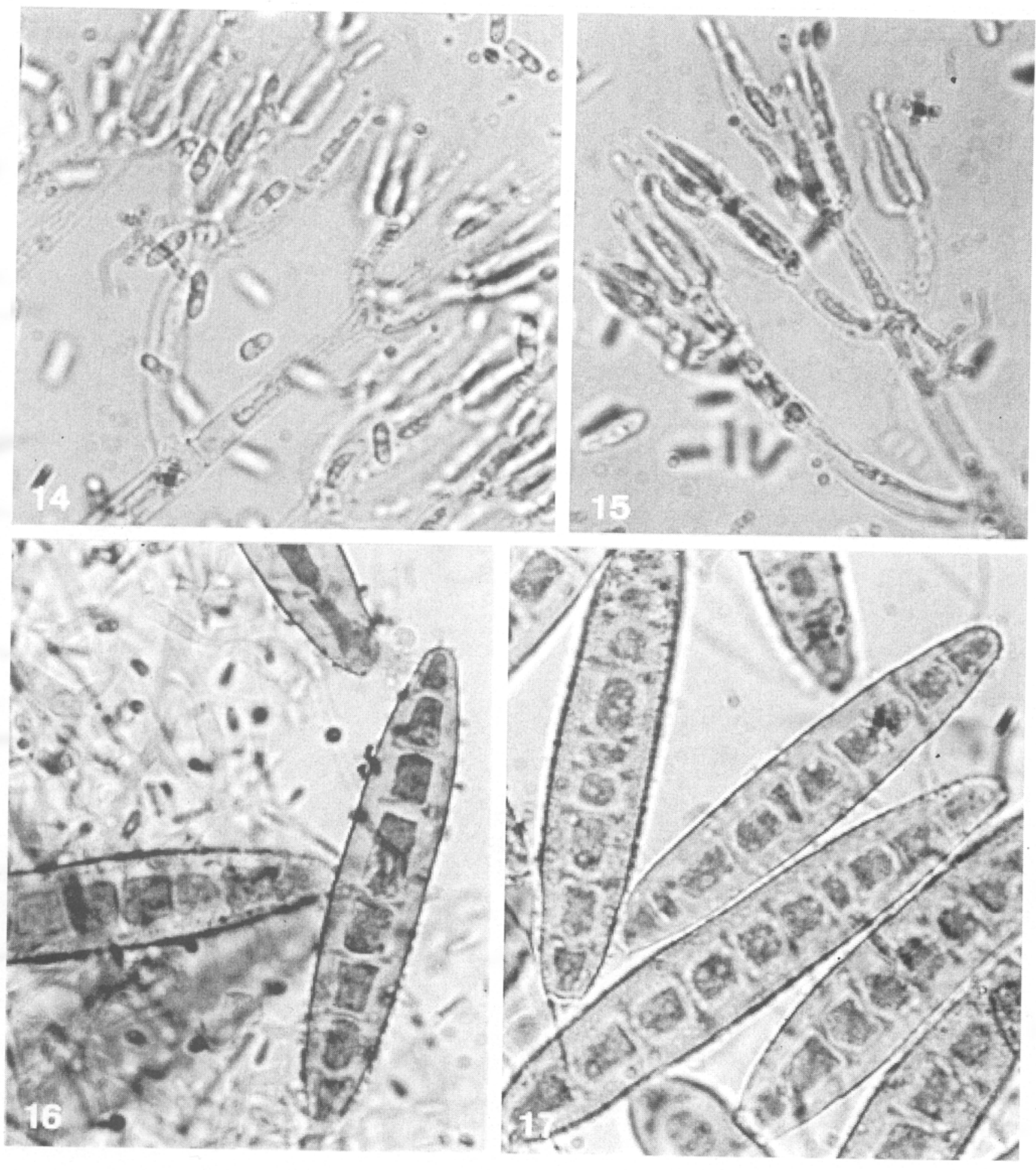

Figura 2 (Página anterior).- 7-8-9. Clonostachys rosea f. rosea 7. Conidióforos primarios verticilados y conidios. 8. Conidióforos secundarios y células conidiógenas. 9. Conidios de conidióforos secundarios. 10-11. C. rhizophaga (similis) 10. Conidióforo y células conidiógenas. 11. Conidios. 12-13. C. compactiuscula 12. Conidióforos y células conidiógenas. 13. Conidios. (Optica normal, todas las fotografias a 1000x).

Figura 3.- 14-15. C.rogersoniana, conidióforos y conidios. 16-17. Microsporum vanbreuseghemii (similis), macro y microconidios. (Optica normal, todas las fotografias a 1000x) 


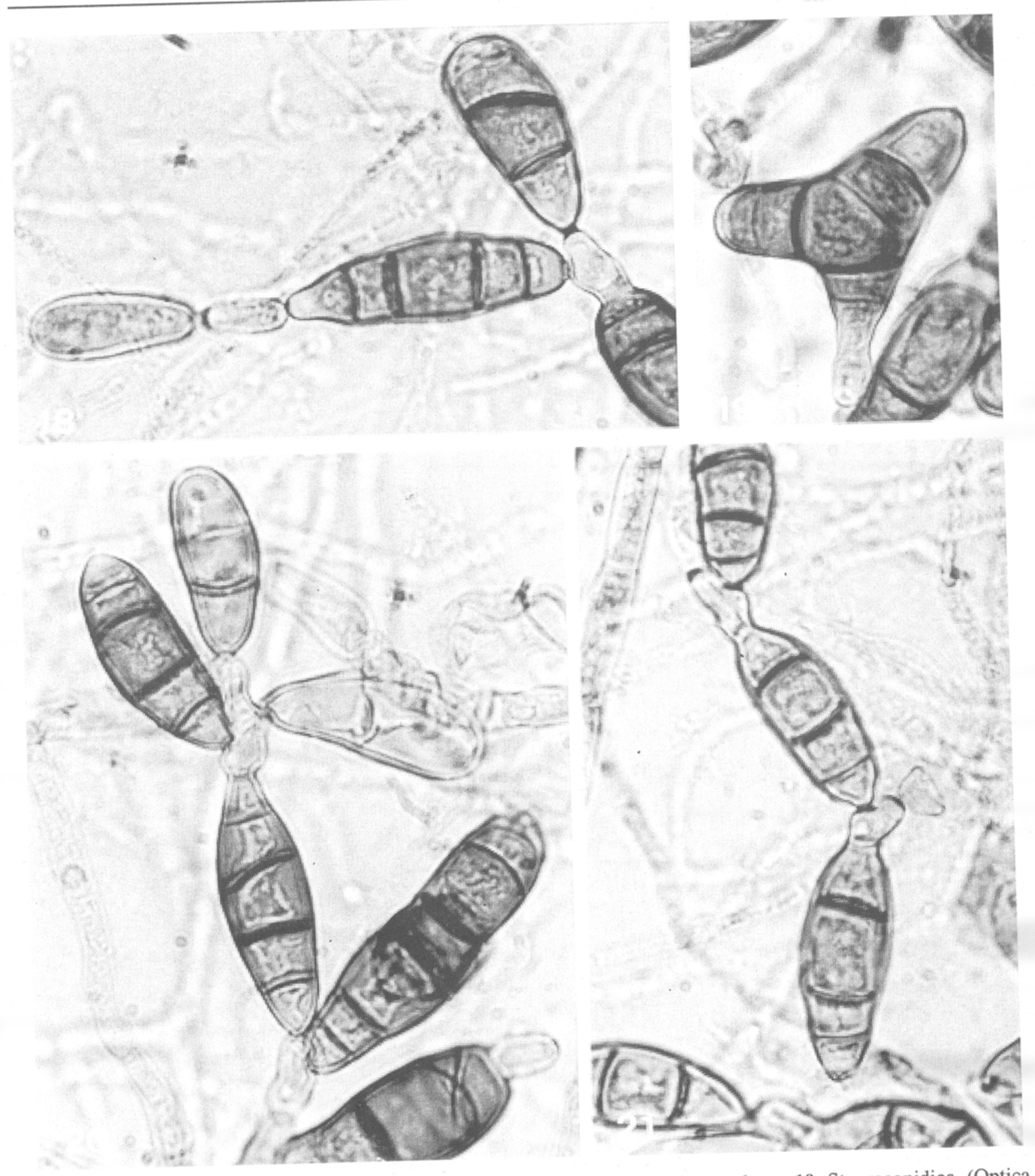

Figura 4- 18-19-20-21. Curvularia catenulata 18-20-21. Fragmoconidios en cadenas 19. Stauroconidios. (Optica normal, todas las fotografias a $1000 \mathrm{x}$ ).

dudosa y que por su formación de cadenas la relaciona más bien con una especie de Alternaria sin septos longitudinales. Sin embargo, a pesar que nuestra cepa muestra ciertos grados de variación con la descripción original tiene rasgos intermedios entre ambas cepas mencionadas y no es tan curva como C.catenulata, situación que puede atribuirse a su localización geográfica y tipo de hospedador. Presenta todas las características del género 
Curvularia, tales como; una célula más grande y más oscura que las otras e incluso la formación de stauroconidios, que a veces se forman entre los conidios normales (Figura 4.- 18,19,20,21), estos conidios son comunes en C. lunata, C. fallax y $\boldsymbol{C}$. penniseti. El aspecto cadenado, según se observa, se debe a la formación de conidióforos apicales que originan nuevos locus conidiógenos que repiten el proceso en el nuevo conidio, dando el aspecto en cadena. Una variación bastante similar al proceso en cadena que se observa en Alternaria u otros géneros con conidios tréticos.

\section{REFERENCIAS}

Alfieri,S.A. \& Samuels, G.J. (1979). Nectriella Potroni and its Kutilakesa-like anamorph, A parasite of ornamental Shrubs. Mycologia 71:1178-1185

Boehme, H. \& Ziegler,H. (1967).Keratinabbau durch Pilze. Arch. Mikrobiol. 57:93-110

Caretta,G.\& Piontelli,E. (1975). Isolation of keratinophilic fungi from soil in Pavia, Italy. Sabouraudia 13:33-37

Georg,L.K.; Ajello,L.; Friedman, L.;Brinkman,S.A.(1962). A new species of Microsporum pathogenic to man and animals. Sabouraudia 1:189-196

Guarro,J.; Hofling-Lima,A.L.; Gené,J.; DeFreitas,D.;Godoy, P.;Zorat.Yu,M.L.; Zaror,L.; Fischman,O. (2002). Corneal ulcer caused by the new fungal species Sarcopodium oculorum. J.Cl. Microbiol. 40:3071-3075

Kano,R.; Matsushiro, H.; Watari,T.; Tsujimoto,H. \& Hasegawa,A. (1997). Differentiation of Arthroderma species by random amplification polymorphic DNA (RAPD) and southern hybridization analyses. Mycoses 40:335-341

Kano,R.; Nakamura,S.; Watanabe,H.; Takahashi,H.; Tsujimoto,H.; Hasegawa,A. (1998). Differentiation of Microsporum species by random amplification polymorphic DNA (RAPD) and southern hybridization analyses. Mycoses 41:229-233

Domsch,K.H.; Gams,W.\& Anderson,T-H. (1980). Compendium of soil fungi. Academic Press London. Velag.

Mercantini,R.; Marsella,R.; Lambiase,L.; Belardi, M. (1986). Isolation of keratinophilic fungi from floors in Roman kindergarten and secondary schools. Mycopathologia 94:109-115

Moriello, K.A. \& DeBoer,D.J. (1991). Fungal flora of the coat of pet cat. Am. J. Vet.Res. 52:602-606

Moubasher,A.; El-Naghy, M.A.;Maghazy, S.M.; El-Gendy,Z. (1993). Dermatophyte and cyclohehimide-resistant fungi isolated from patient with tinea capitis and from air in hospitals in Minia, Egypt. Korean Journal of Mycology 21:77-84

Morganti, L. \& Padhye,A.A. (1975).Recovery of Nannizzia grubyia from a stray italian cat (Felis catus). Mycologia 67:434-436

Olivera,A.C.P.; Kioshima, E.S.; Svidzinski, T.I.E.; Guilhermetti,E.; Pedra, M.R. (2002). Tinea capitis in Maringá, Paraná. An 11 year survey. Anais Brasileiros de Dermatología 77:321-328
Piontelli, E.;Toro, M.A. \& Casanova,D. (1986). Microcomunidades fúngicas en zona altiplánica Chilena. Estudio sobre substratos queratínicos.Rev. Arg. de Micol. 9:26-32

Piontelli, E.;Toro, M.A. \& Casanova,D. (1990). Latitudinal distribution of Onygenales and related Hyphomycetes in soils of northern Chile between 18-34 ${ }^{\circ}$ South Latitude. Boletín Micológico 5:79-106

Rai,M.K. \& Qureshi, S. (1994). Screening of different keratin baits for isolation of keratinophilic fungi. Mycoses 37:295-298

Rehner,S.A. \& Samuels, G.J.(1994). Taxonomy and Phylogeny of Gliocladium analysed from large subunit ribosomal DNA sequences. Mycol. Res. 98:625-634

Rogerson,C.T. \& Stephenson,S.L. (1993). Myxomyceticolous fungi. Mycologia 85:456-469

Satton, B.C. (1981).Sarcopodium and its Synonyms. Trans. Br. mycol.Soc. 76:97-102

Schimmel, T.; Borneman,W. \& Conder,M.J. (1997). Purification and characterization of a lovastatin esterase from Clonostachys compactiuscula. Appl. Environ. Microbiol. 63:1307-1311

Schroers, H-J.; Samuels,G,J.;Seifert,K.A. \& Gams,W. (1999). Classification of the mycoparasite Gliocladium roseum in Clonostachys as C.rosea, its relationship to Bionectria ochroleuca, and notes on other gliocladium -like fungi. Mycologia 91:365-385

Schroers, H-J. (2001). A monograph of Bionectria (Ascomycota, Hypocreales, Bionectriaceae) and its Clonostachys anamorphs. Studies in Mycology 46:1-214

Seifert, K.A. (1985). A Monograph of Stilbella and some allied Hyphomycetes. Studies in Mycology 27: 1-235

Sivanesan, A. (1987). Graminicolous species of Bipolaris, Curvularia, Drechslera, Exserohilum and their teleomorphs. Mycological Papers $\mathrm{N}^{\circ} 158$. CAB. Intern. Mycol. Inst.

Tubaki, K. (1963). Notes on the Japanese Hyphomycetes. I Chloridium, Clonostachys, Isthmospora, Pseudobotrytis, Stachybotrys and Stephanoma. Trans. Mycol. Soc. Japan 4: 83-90

Watanabe,T.(1993). Sarcopodium araliae sp. nov. On root of Aralia elata from Japan. Mycologia 85:520-526 